\title{
Detection of potentially inappropriate prescribing in the very old: cross-sectional analysis of the data from the BELFRAIL observational cohort study
}

Olivia Dalleur ${ }^{1,2^{*}}$, Benoit Boland ${ }^{3}$, Audrey De Groot ${ }^{4}$, Bert Vaes ${ }^{5,6}$, Pauline Boeckxstaens ${ }^{5,7}$, Majda Azermai ${ }^{8}$, Dominique Wouters ${ }^{1}$, Jean-Marie Degryse ${ }^{5,6}$ and Anne Spinewine ${ }^{2,9}$

\begin{abstract}
Background: Little is known about the prevalence and clinical importance of potentially inappropriate prescribing instances (PIPs) in the very old (>80 years). The main objective was to describe the prevalence of PIPs according to START (Screening Tool to Alert doctors to Right Treatment; omissions) and,STOPP (Screening Tool of Older Person's Prescriptions; over/misuse) and the Beers list (over/misuse). Secondary objectives were to identify determinants if PIPs and to assess the clinical importance to modify the treatment in case of PIPs.

Methods: Cross-sectional analysis of baseline data of the BELFRAIL cohort, which included 567 Belgian patients aged 80 and older in primary care. Two independent researchers applied the screening tools to the study population to detect PIPs. Next, a multidisciplinary panel of experts rated the clinical importance of the PIPs on a subsample of 50 patients.

Results: In this very old population (median age 84 years, $63 \%$ female), the screening detected START-PIPs in $59 \%$ of patients, STOPP-PIPs in $41 \%$ and Beers-PIPs in $32 \%$. Assessment of the clinical importance revealed that the most frequent PIPs were of moderate or major importance. In $28 \%$ of the subsample, the relevance of the PIP was challenged by the global medical, functional and social background of the patient hence the validity of some criteria was questioned.
\end{abstract}

Conclusion: Potentially inappropriate prescribing is highly prevalent in the very old. A good understanding of the patients' medical, functional and social context is crucial to assess the actual appropriateness of drug treatment.

Keywords: Inappropriate Prescribing, Aged 80 and older, Primary care, General practice, STOPP\&START, Beers

\section{Background}

Potentially inappropriate prescribing (PIP) is highly prevalent in older adults and has been associated with adverse drug events, hospitalization and death [1-4]. A review reported that the median rate of inappropriate prescribing in primary care was around $20 \%$ in patients aged over 65 years old [5]. But little is known about the prevalence of inappropriate prescribing in the very old,

\footnotetext{
* Correspondence: olivia.dalleur@uclouvain.be

'Pharmacy department, Cliniques universitaires Saint-Luc, Université catholique de Louvain, Brussels, Belgium

${ }^{2}$ Louvain Drug Research Institute (LDRI), Université catholique de Louvain, Brussels, Belgium

Full list of author information is available at the end of the article
}

yet the latter represent a challenge for healthcare, because of multiple comorbidities, polypharmacy, frailty features and increased sensitivity to adverse drug events.

Several approaches exist to detect and reduce the burden of inappropriate prescribing in elderly, including the use of criterion-based screening tools, also called explicit tools $[2,6]$. The most studied explicit tool is the Beers list, which was first published in 1991 [7] and last updated in 2012 [8]. In recent years, another explicit tool, the Screening Tool of Older Person's Prescriptions (STOPP) and Screening Tool to Alert doctors to Right Treatment (START) [9], has been increasingly used [1]. The tool aims at detecting PIP in patients aged over 
65 years old, which was the population target of most of the published studies using this tool. While Beers and STOPP address over- and misuse of inappropriate medications, the START tool allows for the detection of potentially inappropriate drug omissions. Some overlap of content between the STOPP and the 2012 Beers criteria has been described [10-13]. In the very old, to the best of our knowledge, no comparison with the updated 2012 Beers list has been performed. A recent study including inpatients aged 85 years and over measured the prevalence of PIPs according to STOPP\&START and to a previous version of the Beers criteria (2003) [13]. This study showed a high prevalence of PIPs in that very old population (STOPP: 63 \%; START: $54 \%$, Beers: $47 \%$ ) [13]. Moreover, the actual clinical relevance of those tools in the very old is unknown. Indeed, previous studies showed that potentially inappropriate prescribing detected by screening tools might differ from actually inappropriate prescribing [14-16].

The primary objective of this study was to determine the prevalence of PIP in community-dwelling patients aged 80 and older (the BELFRAIL population) [17] according to START (START-PIP), STOPP (STOPP-PIP) and Beers (Beers-PIP) tools.

Secondary objectives included the identification of determinants of PIPs in this population, and assessment of the clinical importance of a subsample of PIPs.

\section{Methods}

\section{Study design, setting and participants}

We performed a cross-sectional analysis of the baseline data of the BELFRAIL cohort $\left(\mathrm{BF}_{\mathrm{C80+}}\right)$ [17]. The BELFRAIL study is a prospective, observational, populationbased cohort study of Belgian subjects aged 80 years and older [17]. The subjects were recruited in Belgium by their general practitioners (GPs) between November 2, 2008 and September 15, 2009, as described elsewhere [17]. This cohort excluded patients with severe dementia (mini mental state examination [18] MMSE <15/30), treated in palliative care and or as medical emergency. The protocol of this study was approved by the Biomedical Ethics Committee of the Medical School of the Université catholique de Louvain (UCL) of Brussels, Belgium (B40320084685). All patients gave written informed consent. Because patients with severe dementia $(\mathrm{MMSE}<15)$ were excluded, all patients were able to give the informed consent themselves.

\section{Data collection}

\section{Medical and background data}

For the 567 patients of the cohort, the GPs performed a detailed medical history and clinical examination [17]. The GPs reported the complete problem list of their patients as free text. Additionally, a structured questionnaire assessed the presence of 22 chronic conditions. Two researchers coded independently all the comorbidities listed by the GPs (OD and PB). Discrepancies were discussed with a third researcher (BV) until a consensus was reached. The Cumulative Illness Rating Scale (CIRS) was calculated [19-21]. The CIRS counts the number of 14 body systems affected with moderate disability, morbidity or extremely severe disease [19-21]. (Score varies from 0 to 14). Background data collection also included: cognitive impairment measured by the MMSE (score $<25$ was considered as "cognitive impairment") [18], geriatric depression scale score GDS-15 (score $>4$ was considered as "possible depression") [22], Tinetti fall risk score (score $>24$ was considered as "low fall risk") [23], functional status according to the activities of daily living (ADL) score (ADL ranged between 6 and 30, lower score is related to functional dependency) [24], incontinence (reported by the GP), body mass index, familial status, and place of residence.

\section{Drugs and inappropriate prescribing}

GPs were asked to list the drugs the patient was taking on a regular basis or as needed. Drugs were coded and classified according to the Anatomical Therapeutic Chemical (ATC) classification system by one researcher (MA) [25].

Two researchers (OD and $A D)$ independently retrospectively applied the 87 criteria of the STOPP\&START tool [9] and the 3 categories of Beers' criteria (drugs to avoid, to avoid regarding certain conditions/diseases, and to use with caution) [8] to the coded medical conditions and drugs. Discrepancies were discussed until consensus. For the analysis of the secondary outcomes, the Beers drugs to use with caution were not considered.

\section{Determinants of PIP}

Potential determinants of PIPs were tested among the following variables: medical (CIRS categorized as $<4$, or $=4$, or $>4$ ), geriatric (polypharmacy [ $\geq 5$ drugs/day], MMSE [>25 (no cognitive impairment) or 20-24 or <20], ADL adjusted for gender [lowest quintile (higher dependence) or higher quintiles], GDS-15 [< or $\geq 5$ (possible depression)], Tinetti score [25-28 (lowest fall risk) or 19-24 or $\leq 18]$, incontinence, body mass index $\left[<\right.$ or $\left.\geq 21 \mathrm{~kg} / \mathrm{m}^{2}\right]$ $[26,27])$ and social (age, gender, institutionalisation).

\section{Clinical importance}

On a randomly selected subsample of 50 patients, an expert panel (a general practitioner (JD), a geriatrician (BB) and a clinical pharmacist (AS), all with research experience in the field) was asked to independently rate the actual clinical importance of the recommendations (i.e., to add the drugs suggested by START to the treatment, or to discontinue the drugs detected by STOPP or 
Table 1 Characteristics of the patients of the BELFRAIL cohort $(N=567)$

\author{
Characteristics of the patients \\ Age (years), median [Q25;Q75] \\ Gender, women, n (\%) \\ Resident in a nursing home, $\mathrm{n}(\%)$ \\ Number of drugs/day, median [Q25;Q75] \\ Geriatric features \\ Polypharmacy ( $\geq 5$ drugs/day), n (\%) \\ $\mathrm{ADL},{ }^{a}$ median $[\mathrm{Q} 25 ; \mathrm{Q} 75]$ \\ Living alone at home, $\mathrm{n}(\%)$ \\ Urinary incontinence, $\mathrm{n}(\%)$ \\ Cognitive impairement, $\mathrm{n}(\%)$ \\ $\mathrm{BMI}<21 \mathrm{~kg} / \mathrm{m}^{2}, \mathrm{n}(\%)$ \\ MMSE, median [Q25;Q75] \\ Tinetti score, ${ }^{\mathrm{C}}$ median [Q25;Q75] \\ GDS-15, ${ }^{\mathrm{d}}$ median [Q25;Q75] \\ CIRS median [Q25;Q75]
}

Most frequent comorbidities

Hypertension, $\mathrm{n}(\%)$
Osteoarthritis, $\mathrm{n}(\%)$
Ischemic disease, $\mathrm{n}(\%)$
Chronic heart failure, $\mathrm{n}(\%)$
Chronic renal disease (GFR < $50 \mathrm{ml} / \mathrm{min}), \mathrm{n}(\%)$
Osteoporosis, $\mathrm{n}(\%)$
Diabetes, $\mathrm{n}(\%)$
Depression, $\mathrm{n}(\%)$
COPD, $\mathrm{n}(\%)$
Atrial fibrillation $\mathrm{n}(\%)$

Most frequent drugs prescribed, $\mathrm{n}$ patients (\%)

$\begin{array}{ll}\text { Antithrombotic agents (B01) } & 312(55.0) \\ \text { Beta-blocking agents (C07) } & 238(42.0) \\ \text { Agents acting on the renin-angiotensin system (C09) } & 237(41.8) \\ \text { Psycholeptics (N05) } & 220(38.8) \\ \text { Diuretics (C03) } & 189(33.3) \\ \text { Lipid Modifying Agents (C10) } & 180(31.7) \\ \text { Drugs for acid related disorders (A02) } & 138(24.3) \\ \text { Calcium Channel Blockers (C08) } & 135(23.8) \\ \text { Psychoanaleptics (N06) } & 131(23.1) \\ \text { Cardiac Therapy (C01) } & 115(20.3)\end{array}$

Potentially inappropriate prescribing, $\mathrm{n}$ patients (\%)
Table 1 Characteristics of the patients of the BELFRAIL cohort $(N=567)$ (Continued)

\begin{tabular}{ll}
\hline START-PIPS & $336(59.3)$ \\
STOPP-PIPS & $232(40.9)$ \\
Beers-PIPS & $180(31.7)$ \\
\hline
\end{tabular}

Abbreviations: $A D L$ activities of daily living, $B M I$ body mass index, CIRS cumulative illness rating scale, COPD chronic obstructive pulmonary disease, GDS geriatric depression scale, GFR glomerular filtration rate, MMSE mini mental state examination, PIPs potentially inappropriate prescribing ${ }^{\mathrm{a}} \mathrm{ADL}$ ranged between 6 and 30, lower score is related to functional dependency

"MMSE $<25$ was considered as "cognitive impairment"

"Tinetti score $>24$ was considered as "low fall risk"

"GDS-15 score $>4$ was considered as "possible depression"

Beers). Recommendations were classified following a previously defined method as minor, moderate, major, extreme, deleterious or not applicable (description of classifications can be found in Table 4) [14, 28]. Consensus on the clinical importance was reached when 2 experts agreed. To assess PIPs in the thorough context of the patient, the panel had access to the full record provided by the GP, and not only the coded conditions.

\section{Statistical analysis}

Normally distributed continuous variables were expressed as mean \pm standard deviation, while not normally distributed ones were summarized using the median and the inter-quartile range [Q25;Q75]. For categorical variables, numbers and percentages were presented. A univariate analysis and a multivariate logistic regression analysis were used to identify determinants of potentially inappropriate prescribing according to each tool. Variables with a $p$ value of $<0.05$ in the univariate analysis were submitted for multivariate regression analysis. A $p$ value $<0.05$ was considered statistically significant in the multivariate analysis. Statistical analyses were performed using IBM SPSS Statistics 20 (SPSS Inc., Chicago, IL, USA).

\section{Results}

The characteristics of the 567 patients included at baseline in the cohort are presented in Table 1. Patients had a median age of 84 years, $63 \%$ were female and they lived mainly at home (90\%). The most frequent comorbidities they presented were: hypertension $(70 \%)$, osteoarthritis (57 \%) and ischemic disease (37 \%). Eighty-one percent of the patients had at least one PIP in their medications: 59 \% had START-PIPs (drug omissions), $41 \%$ had STOPP-PIPs and $32 \%$ had Beers-PIPs (drug overuse and/or misuse).

\section{Inappropriate prescribing}

Overall, we found $1.13 \pm 1.34$ START-PIP per patient; range $0-8$. In the $59 \%$ of patients having at least one START-PIP, the average of START-PIPs rose to $1.90 \pm$ 1.25 per affected patient. 
Patients had on average $0.58 \pm 0.92$ STOPP-PIP in their list of prescriptions; range $0-10$. The $41 \%$ of affected patients had $1.43 \pm 0.95$ STOPP-PIP in their treatment.

The application of the Beers tool pointed out Beers-PIPs as drugs to avoid or to avoid in the presence of certain conditions in $32 \%$ of the patients. The mean number of Beers-PIP in the treatment was $0.44 \pm 0.79$ per patient; range $0-6$. In patients having at least one Beers-PIP, the average was $1.38 \pm 0.80$ per affected patient. In addition, Beers drugs that are labelled to be used with caution were found in $45 \%$ of the patients.

Overall, 108 patients out of the 567 (19\%) had no PIP at all when considering START, STOPP and Beers tools. The most frequent PIPs are presented in Table 2. As far as underuse was concerned, the most frequent drug category using START was cardio-vascular (antiplatelet, statin, angiotensin-converting-enzyme inhibitors). The most frequent drug categories related to misuse or overuse were cardiovascular and psychotropic drugs (aspirin, benzodiazepines) and similar using STOPP and Beers. The prevalence of PIPs related benzodiazepine use with history of falls was less than $1 \%$ (one patient). However, $19 \%$ of the patients on benzodiazepines were at high fall risk according to their Tinetti score, and could therefore be assimilated to patients having PIPs.

\section{Determinants of PIP}

The results of the multivariate analysis are shown in Table 3. A lower comorbidity score was a determinant of lower odds of having START-PIPs (odds ratio [OR] $0.2,95 \%$ confidence interval [CI] $0.1-0.3$ for CIRS $<4$ vs. $>4$ ). Functional dependence (lowest quintile of ADL, range in women $6-18$, range in men 6-21) was the only determinant of having STOPP-PIP (OR 1.5, 95 \% CI 1.0-2.4). Beers-PIPs were also associated with the CIRS (OR 0.4, $95 \%$ CI $0.3-0.7$ for CIRS $<4$ vs. $>4$, and OR $0.6,95 \%$ CI $0.4-0.9$ for CIRS $=4$ vs. $>4$ ). Living in a nursing home was another determinant of Beers-PIPs (OR 1.8, 95 \% CI 1.0-3.4). Other social and geriatric features were not related to PIPs.

\section{Clinical importance of the recommendations to modify the treatment in the presence of PIP}

In the subsample of 50 patients, the experts examined 143 PIPs (i.e.,: 44 STOPP-PIPs, 65 START-PIPs and 34 BeersPIPs [including 3 PIPs overlapping the STOPP-PIPs], concerning 17 different criteria of the START tool, 18 criteria from STOPP and 20 criteria from Beers). The experts

Table 2 Most frequent potentially inappropriate prescribing events according to START, STOPP and/or Beers criteria

\begin{tabular}{|c|c|c|}
\hline & Therapeutic class/medication \pm disease & Prevalence \% (n) \\
\hline \multicolumn{3}{|c|}{$\begin{array}{l}\text { Under prescribing according to } \\
\text { START }\end{array}$} \\
\hline & $\begin{array}{l}\text { Aspirin or clopidogrel with a documented history of atherosclerotic coronary, cerebral or } \\
\text { peripheral vascular disease in patients with sinus rhythm }\end{array}$ & $15,0(85)$ \\
\hline & Calcium and vitamin D supplement in patients in the presence of known osteoporosis & $13,9(79)$ \\
\hline & ACE inhibitor in the presence of chronic heart failure & $12,7(72)$ \\
\hline & $\begin{array}{l}\text { Statin therapy with a documented history of coronary, cerebral or peripheral vascular } \\
\text { disease, where the patient's functional status remains independent for activities of daily } \\
\text { living and life expectancy is greater than } 5 \text { years }\end{array}$ & $9,5(54)$ \\
\hline & $\begin{array}{l}\text { Antiplatelet therapy in diabetes mellitus with coexisting major cardiovascular risk factors } \\
\text { (hypertension, hypercholesterolemia, smoking history) }\end{array}$ & $9,5(54)$ \\
\hline \multicolumn{3}{|c|}{$\begin{array}{l}\text { Over/misprescribing according to } \\
\text { STOPP or/and Beers }\end{array}$} \\
\hline STOPP and Beers & Aspirin for primary cardiovascular prevention ${ }^{a}$ & $16,9(96)$ \\
\hline Beers & Nonbenzodiazepine ("Z") hypnotics (i.e., eszoplicone, zaleplon, zolpidem) & $6,2(35)$ \\
\hline STOPP & Any duplicate drug class prescription & $6,2(35)$ \\
\hline Beers & Benzodiazepines in the presence of dementia and cognitive impairment & $5,8(33)$ \\
\hline STOPP and Beers & Long-acting benzodiazepines & $4,9(28)$ \\
\hline STOPP & Aspirin at dose $>150 \mathrm{mg} /$ day & $4,4(25)$ \\
\hline STOPP & NSAIDs with moderate to severe hypertension & $3,7(21)$ \\
\hline Beers & Tertiary TCAs, alone or in combination & $2,6(15)$ \\
\hline
\end{tabular}

Abbreviations: ACE angiotensin-converting-enzyme, NSAIDs nonsteroidal anti-inflammatory drugs, TCA tricyclic antidepressant

${ }^{a}$ To be used with caution in adults $>80$ years old for primary prevention of cardiac events in Beers 2012; to be avoided in those with no history of coronary, cerebral, or peripheral vascular symptoms or occlusive events in STOPP 
Table 3 Determinants of potentially inappropriate prescribing in the study population (multivariate analysis)

\begin{tabular}{|c|c|c|c|}
\hline & Covariates & OR $[95 \% \mathrm{Cl}]$ & $p$ value \\
\hline \multicolumn{4}{|l|}{ START-PIP } \\
\hline & ADL lowest quintile ${ }^{a}$ & $0.8[0.4-1.5]$ & 0,523 \\
\hline & Age, per year & $1.0[0.9-1.1]$ & 0,227 \\
\hline & CIRS $>4$ & 1.0 & \\
\hline & CIRS $<4$ & $0.2[0.1-0.3]$ & $<0,001$ \\
\hline & $\mathrm{CIRS}=4$ & $0.6[0.3-1.1]$ & 0,090 \\
\hline & GDS-15 > $4^{b}$ & $1.2[0.7-2.0]$ & 0,442 \\
\hline & Gender, women & $0.9[0.6-1.4]$ & 0,727 \\
\hline & Tinetti $\leq 18^{c}$ & 1.0 & \\
\hline & Tinetti 25-28 & $0.5[0.2-1.2]$ & 0,130 \\
\hline & Tinetti 19-24 & $0.9[0.3-2.2]$ & 0,840 \\
\hline \multicolumn{4}{|l|}{ STOPP-PIP } \\
\hline & ADL lowest quintile & $1.5[1.0-2.4]$ & 0.050 \\
\hline & Age, per year & $1.0[0.9-1.0]$ & 0.957 \\
\hline & Gender, women & $1.2[0.9-1.8]$ & 0.211 \\
\hline & Resident in a nursing home & $1.8[0.9-3.2]$ & 0.056 \\
\hline \multicolumn{4}{|l|}{ BEERS-PIP } \\
\hline & ADL lowest quintile & $1.1[0.7-1.9]$ & 0.558 \\
\hline & Age, per year & $0.9[0.9-1.0]$ & 0.515 \\
\hline & CIRS $>4$ & 1.0 & \\
\hline & CIRS $<4$ & $0.4[0.3-0.7]$ & $<0.001$ \\
\hline & $\mathrm{CIRS}=4$ & $0.6[0.4-0.9]$ & 0.041 \\
\hline & GDS-15 >4 & $1.5[0.9-2.3]$ & 0.094 \\
\hline & Gender, women & $1.2[0.8-1.8]$ & 0.364 \\
\hline & Resident in a nursing home & $1.8[1.0-3.4]$ & 0.045 \\
\hline
\end{tabular}

Hosmer-Lemeshow goodness-of-fit $P$-value for START $=0.42 ;$ STOPP $=0.15$; Beers $=0.89$ indicating that the models are a good fit for the data Abbreviations: $A D L$ activities of daily living, $C I$ confidence interval, CIRS cumulative illness rating scale, GDS geriatric depression scale, $O R$ odds ratio, PIPs potentially inappropriate prescribing

${ }^{\mathrm{a}} \mathrm{ADL}$ lowest quintile: lower $\mathrm{ADL}$ score is related to functional dependency bGDS-15 score $>4$ was considered as "possible depression"

"Tinetti score $>24$ was considered as "low fall risk"; $\leq 18$ was "high fall risk"

agreed on the clinical importance of $83 \%$ of the PIPs. The clinical importance of the same criterion could vary in different patients according to each patient's individual context.

Forty-three PIPs cases (30 \%) were rated of "major" importance, while 33 PIPs (23\%) were considered of moderate importance. The experts rated two PIPs as "minor". One START-PIP appeared to be "deleterious". Examples are provided in Table 4. Finally, the experts agreed that 40 PIPs (28\%) were "non-applicable" according to the individual context and even considered 19 of those cases (13\%) as actually appropriate prescribing.

The 40 "non applicable" cases could be divided into two categories. The first category encompassed 25 cases where the experts found nuances within the detailed full record of the patient, including the comprehensive geriatric assessment, which questioned the applicability of the criteria. In the second category $(n=15)$, the experts questioned the content validity of the criteria. Examples are provided in Table 5. Comparing the PIPs detected by the three tools, START-PIPs were the most frequently rated as "non applicable".

\section{Discussion}

\section{Summary}

For the first time, this study described inappropriate prescribing and their determinants in a large representative sample of community-dwelling very old patients. In this population, the prevalence of PIPs was high. Potentially inappropriate omissions, detected by the START tool were more prevalent (59 \% of the patients) than overuse of treatment (STOPP: $41 \%$; Beers' drugs "to avoid": $32 \%)$. Drugs from the cardiovascular and neurologic systems were the most frequently involved in PIPs. Among medical, social and geriatric features, the CIRS was related to having START- and Beers-PIPs, place of residency was associated with Beers-PIPs and the functional dependence was determinant of having STOPPPIPs.

The evaluation of the relevance of the criteria showed that a holistic approach of the patient changed the applicability of the criteria in $17 \%$ of PIP cases. More importantly, in $10 \%$ of cases, the recommendation to modify the drug regimen was not valid, and could even be considered as deleterious, which is not acceptable. Finally, the experts did not rate similarly the clinical importance of the criteria in $17 \%$ of cases. This illustrates the subjectivity of the assessment of the patient's context and the variable importance acknowledged to inappropriate prescribing according to the evaluator.

\section{Comparison with existing literature}

The prevalence detected in our patients aged 80 and older (START : 59 \%; STOPP: 41 \%; Beers' drugs "to avoid": $32 \%$ ) did not substantially differ from the prevalence reported in the literature with populations including younger patients in whom the range of prevalence of START-PIP is 23 to $68 \%$ [29-32], STOPP-PIP 18-60\% [30, 32-37], and Beers-PIP 12.5-42 \% [38, 39]. This observation is consistent with a study published in 2015 that compared the prevalence of START-PIPs, STOPPPIPs and Beers-PIPs in patients aged between 75 and 84 years vs patients aged 85 and over, in the hospital setting [13]. The prevalence of PIPs was similar in both groups [13]. It should be noted that prevalence of PIPs varies greatly from studies, depending of the setting and the range of the criteria of the tools that were taken into account. 
Table 4 Clinical importance of potentially inappropriate prescribing criteria according to the expert panel

\begin{tabular}{ll}
\hline Examples & \\
\hline Major & Modification of the \\
clinical & treatment according to \\
importance & this criteria may \\
$(n=43)$ & prevent serious \\
& morbidity, including \\
& readmission, serious \\
& organ dysfunction, \\
& serious adverse drug \\
& event
\end{tabular}

$\begin{array}{ll}\text { Moderate } & \text { Modification of the } \\ \text { clinical } & \text { treatment according to } \\ \text { importance } & \text { this criteria brings care } \\ (n=33) & \text { to a more acceptable } \\ & \text { and appropriate level } \\ & \text { of practice or that may } \\ \text { prevent an adverse } & \text { drug event of } \\ & \text { moderate importance }\end{array}$

Criterion: START-PIP "Angiotensin converting enzyme (ACE) inhibitor with chronic heart failure"

Criterion: STOPP-PIP "Calcium channel blockers with NYHA class III or IV heart failure"/Beers- PIP "Diltiazem in heart failure".

Criterion: Beers- PIP "Anticholinergics in dementia and

cognitive

impairment".
Criterion: START-PIP "Statin therapy in diabetes mellitus if coexisting major cardiovascular risk factors present".

Criterion: STOPP-PIP "Long-term longacting benzodiazepines".

Criterion: STOPP-PIP/ Beers-PIP "Aspirin in primary

cardiovascula prevention".

Criterion: Beers- PIP "Tertiary tricyclic antidepressants".

\footnotetext{
Minor Modification of the clinical treatment according to importance these criteria brings no $(n=2) \quad$ benefit or minor benefit, depending on professional interpretation
}

Context: The GP reports chronic heart failure, with marked limitation of physical activity and dyspnea and a recent episode of congestive heart failure.

Context: The medical history and the clinical examinat examination confirm NYHA class III heart failure.

Context: The patient has cognitive impairment (MMSE = $22 / 30^{\mathrm{a}}$ ) and takes several drugs with anticholinergic properties (amisulpride, trihexyfenidyl) that the patient has

Table 4 Clinical importance of potentially inappropriate prescribing criteria according to the expert panel (Continued)

\begin{tabular}{|c|c|c|c|}
\hline & & $\begin{array}{l}\text { Criterion: Beers-PIP } \\
\text { "Avoid antiarrhythmic } \\
\text { drugs as first-line } \\
\text { treatment of atrial } \\
\text { fibrillation". }\end{array}$ & $\begin{array}{l}\text { Context: This patient } \\
\text { receives amiodarone } \\
\text { and does not suffer } \\
\text { from any side effect of } \\
\text { this drug. }\end{array}$ \\
\hline & & $\begin{array}{l}\text { Criterion: Beers-PIP } \\
\text { "Avoid long duration } \\
\text { sulfonylurea". }\end{array}$ & $\begin{array}{l}\text { Context: The patient is } \\
\text { on gliclazide extended } \\
\text { release formula. He is } \\
\text { intolerant to } \\
\text { metformine. No } \\
\text { hypoglycemia were } \\
\text { reported. }\end{array}$ \\
\hline \multirow[t]{2}{*}{$\begin{array}{l}\text { Deleterious } \\
\text { clinical } \\
\text { importance } \\
(n=1)\end{array}$} & $\begin{array}{l}\text { Modification of the } \\
\text { treatment according to } \\
\text { this may lead to } \\
\text { adverse outcome. }\end{array}$ & & \\
\hline & & $\begin{array}{l}\text { Criterion: START-PIP } \\
\text { "Statin therapy in } \\
\text { diabetes mellitus if } \\
\text { coexisting major } \\
\text { cardiovascular risk } \\
\text { factors present". }\end{array}$ & $\begin{array}{l}\text { Context: The patient } \\
\text { has a documented } \\
\text { allergy to statins. }\end{array}$ \\
\hline \multirow[t]{7}{*}{$\begin{array}{l}\text { Non } \\
\text { applicable } \\
(n=40)\end{array}$} & $\begin{array}{l}\text { The criterion is not } \\
\text { applicable to the } \\
\text { individual context of } \\
\text { the patient. }\end{array}$ & & \\
\hline & & $\begin{array}{l}\text { Criterion: START-PIP } \\
\text { "beta-blocker with } \\
\text { chronic stable } \\
\text { angina". }\end{array}$ & $\begin{array}{l}\text { Context: The patient } \\
\text { had a single episode } \\
\text { of suspected angina in } \\
\text { the past, and he has } \\
\text { asthma. }\end{array}$ \\
\hline & & $\begin{array}{l}\text { Criterion: START-PIP } \\
\text { "Aspirin therapy in } \\
\text { diabetes mellitus if } \\
\text { coexisting major } \\
\text { cardiovascular risk } \\
\text { factors present". }\end{array}$ & $\begin{array}{l}\text { Context: The patient is } \\
\text { already on anti- } \\
\text { vitamin } \mathrm{K} \text { and he has } \\
\text { no acute coronary } \\
\text { disease. }\end{array}$ \\
\hline & & $\begin{array}{l}\text { Criterion: STOPP-PIP } \\
\text { "Any duplicate drug } \\
\text { class prescription". }\end{array}$ & $\begin{array}{l}\text { Context: The } \\
\text { prescription includes a } \\
\text { patch of nitroglycerin } \\
\text { and tablets of } \\
\text { isosorbide dinitrate. } \\
\text { However, in his notes, } \\
\text { the GP specifies that } \\
\text { the patient uses the } \\
\text { tablets "as needed" } \\
\text { only. }\end{array}$ \\
\hline & & $\begin{array}{l}\text { Criterion: STOPP-PIP } \\
\text { "Long-term use of } \\
\text { NSAID for symptom } \\
\text { relief of mild } \\
\text { osteoarthritis". }\end{array}$ & $\begin{array}{l}\text { Context: The } 83 \text { year } \\
\text { old patient has } \\
\text { chronic knee pain } \\
\text { despite the use of } \\
\text { paracetamol. } \\
\text { Unfortunately, his } \\
\text { severe respiratory and } \\
\text { cardiac status is a } \\
\text { contra-indication to } \\
\text { surgery and he is } \\
\text { intolerant to } \\
\text { alternatives to NSAID. } \\
\text { He is on proton-pump } \\
\text { inhibitor. }\end{array}$ \\
\hline & & $\begin{array}{l}\text { Criterion: Beers-PIP } \\
\text { "Avoid antipsychotics } \\
\text { in dementia \& } \\
\text { cognitive } \\
\text { impairment". }\end{array}$ & $\begin{array}{l}\text { Context: This patient } \\
\text { has cognitive } \\
\text { impairment but also a } \\
\text { long story of } \\
\text { psychiatric disorders. }\end{array}$ \\
\hline & & $\begin{array}{l}\text { Criterion: Beers-PIP } \\
\text { "Avoid } \\
\text { benzodiazepines for } \\
\text { the treatment of } \\
\text { insomnia, agitation, or } \\
\text { delirium". }\end{array}$ & $\begin{array}{l}\text { Context: This patient } \\
\text { received alprazolam to } \\
\text { improve her sleep in a } \\
\text { context of severe } \\
\text { chronic anxiety. }\end{array}$ \\
\hline
\end{tabular}

Context. The patient is 87 years, and still has good cognitive and functional status. She has diabetes, hypertension and hypercholesterolemia.

Context: The patient has been taking $8 \mathrm{mg}$ prazepam every day for more than a month. She has low fall risk (Tinetti score $26 / 28^{\text {b }}$ ) but she has cognitive impairment (MMSE=18/30).

Context: The patient has no history of coronary, cerebral or peripheral vascular symptoms or occlusive event.

Context: The patient is on clomipramine for "depressive

tendencies" according to the GP. The GDS-15 score is low $\left(3 / 15^{\circ}\right)$. Non pharmacologic or safer alternatives are available.

Abbreviation: GDS-15 geriatric depression scale, GP general practitioner, MMSE mini mental state examination, NSAID non-steroidal anti-inflammatory drugs, NYHA New York Heart Association Functional Classification, PIP potentially inappropriate prescribing

aMMSE $<25$ was considered as "cognitive impairment"

'Tinetti score $>24$ was considered as "low fall risk"

"GDS-15 score >4 was considered as "possible depression" 
Table 5 How a holistic approach of the patient challenges the PIPs detected by explicit screening tools

Elements of the patient's record that influence the applicability of the criteria $^{\mathrm{a}}$

- Level of severity of a disease

- Certainty of the diagnoses

- Timing of the medical history (recent event vs. long ago)

- Actual intake of the drug that differs from the prescription

- Patient's preferences and objectives

- Mental status of the patient and associated psychiatric conditions

- Absence of alternative treatment

- Patient's pain status

- Drug-drug interactions

- Risk factors for bleeding or for stroke

- Contra-indication

- Allergies

Situations that question the content validity of the criteria:

- START-PIP in patients already treated by suitable alternative medications e.g., "Proton pump inhibitor with severe gastroesophageal acid reflux disease" in a patient already on histamine H2-receptor antagonist.

- START-PIP "Warfarin in the presence of chronic atrial fibrillation" in patients with low stroke risk

- START-PIP "Regular inhaled $\beta 2$-agonist or anticholinergic agent for mild-to-moderate asthma or COPD" in a patient with asthma due to acid reflux

- STOPP-PIP "Any duplicate drug class prescription" because insufficiently defined.

- Beers-PIPs mentioning that a medication should be avoided as "first-line therapy" because such a feature is often difficult to detect

- Beers-PIP "Avoid antidepressants in dementia \& cognitive impairment" in a patient with severe depression

asee examples in Table 4

In younger patients, STOPP-PIPS have been related to polypharmacy, age, institutionalisation, and increased comorbidity), while START-PIPs were variably related to age, female gender, and increased comorbidity $[1,13,40]$. Our results confirm the importance of the comorbidity burden in the risk of having PIPs.

Only a few previous studies looked at the clinical importance of PIPs detected by explicit tools in patients [14-16]. Our analysis on the subsample showed the same trends as previous studies on the Beers list $[15,16]$ and STOPP [14]: a substantial proportion of PIPs were actually appropriate, the relevance varied according to the drug type and some criteria appeared less controversial than others (Table 5). Our review of the subsample of patients reinforces the idea that PIPs are actually only potential and that solely looking at the criteria is not sufficient to decide if the prescribing is inappropriate or not. A holistic approach to the patient challenges the PIPs detected by explicit screening tools, as illustrated in Table 5 .

\section{Strengths and limitations}

This study goes one step further than previous observational studies on PIPs, by providing important findings about the validity of the use of explicit tools and highlighting how a holistic approach matters when reviewing the treatment.

This study presents some limitations. The data used to detect PIPs were not prospectively collected for the purpose of this analysis. Therefore, the quantity of PIPs might have been underestimated. For example, PIPs related to the history of falls, which were frequently reported in previous studies [41], were infrequent in our study (likely due to under-reporting of falls as a medical condition by GPs). However, we observed that a fifth of the patients on benzodiazepines were at high fall risk. Criteria related to delirium and dementia were expected to be infrequently encountered because these patients were excluded from the cohort.

The analysis on the clinical relevance of the criteria was only performed on a small subsample of PIPs. This assessment was designed to provide an insight but did not intend to comprehensively evaluate the content of the full criteria lists. Further studies should assess the actual inappropriateness of all the drugs listed on the tools in larger extent. However, this subsample allowed to discuss the most frequent PIPs and enabled us to identify several important points for discussion on the validity of the tools.

\section{Implications for research and/or practice}

Based on this analysis, including the examples detailed in Table 5, we suggest some important modifications to the tools to improve their validity and applicability (Table 6). The main suggestion for the future use of screening tools in daily practice is that these tools can only be used in addition of an assessment of actual appropriateness of prescribing by clinicians with a good understanding of the patient global health situation and full access to the patient's history. In many ways, the GP appears as the foremost potential user of the tools. Indeed, the GP knows the patient the best, thanks to a long relationship and global vision of the patient

Table $\mathbf{6}$ Recommendations to improve the validity and applicability of explicit tools

\begin{tabular}{ll}
\hline $\begin{array}{l}\text { Recommendations to improve the } \\
\text { validity of the criteria }\end{array}$ & $\begin{array}{l}\text { Recommendations to improve the } \\
\text { applicability of the criteria }\end{array}$ \\
\hline - mention of contra-indications of the criteria & $\begin{array}{l}\boldsymbol{\cdot} \text { clear definitions (conditions, diseases, drug categories) } \\
\text { - no contradictions between criteria }\end{array}$ \\
$\begin{array}{l}\cdot \text { monitoring tips } \\
\text { - no overlap between criteria }\end{array}$ & $\begin{array}{l}\cdot \text { suggestions of alternatives (pharmacological and } \\
\text { non-pharmacological) }\end{array}$ \\
$\begin{array}{l}\text { (inclusion criteria) } \\
\text { - mention of time to benefit }[45,46]\end{array}$ & $\begin{array}{l}\cdot \text { mention of adaptation to functional and cognitive status, } \\
\text { life-expectancy, and multimorbidity. }\end{array}$ \\
\hline
\end{tabular}


medical, social and functional status. Very recently, an updated version of the STOPP\&START tool was published [42]. Some of the criteria for which the validity was questioned in our study have been removed. However, we believe that most recommendations in Table 6 remain valid. Moreover, the message about the paramount importance of using the tools as part of a holistic approach is applicable to any explicit criteria list.

Our results therefore somewhat question the application of explicit screening tools to administrative databases. This approach, which was regularly performed in previous studies [34, 43], is valuable to have a global insight into PIPs patterns and the most frequently encountered drugs. But the prevalence and frequencies should be interpreted with caution. Issues identified can only be deemed potentially inappropriate owing to the limited clinical information available in such databases. Application of explicit tools to large databases should be refined so as to take into account factors that decrease applicability of some criteria (e.g., contra-indications or presence of alternative drugs for START criteria).

Perspectives for future research are provided by this baseline analysis of the BELFRAIL cohort. Longitudinal analysis should compare the incidence of geriatric adverse events (death, hospital admissions, falls, adverse drug events) and costs of care in patients having or not confirmed PIPs at baseline. Additional qualitative research could enlighten some of the barriers to implement screening tools. Furthermore, the viewpoint of the patient on the appropriateness of his own treatment should be explored.

\section{Conclusions}

Our observations highlight the high prevalence of PIPs in very old patients in primary care. The medication review should be part of a comprehensive process to optimize pharmacotherapy. Explicit tools help to revise the treatment but will never replace good clinical judgement [44]. The general practitioner plays a key-role in the management of chronic drug treatment and is therefore potentially in the best position to collaborate and to apply the explicit tool. A good understanding of the patients' medical, functional and social context is crucial to assess the actual appropriateness of drug treatment.

\section{Competing interests}

The authors have no conflicts of interest that are directly relevant to the content of this article.

\section{Authors' contributions}

$B V, J M D$ and $B B$ conceived of the study, and participated in its design and coordination. $\mathrm{OD}, \mathrm{BV}, \mathrm{AS}, \mathrm{JMD}$ and $\mathrm{BB}$ participated in the design of the study. OD, AD, BV, PB and MA participated in the data collection and analysis. $O D$ and $A D$ performed the statistical analysis and wrote the first draft of the study. AS and DW helped with coordination. All authors helped to draft the manuscript, critical reviewing of the manuscript and approved the final manuscript.

\section{Acknowledgements}

This study was only possible thanks to the participating GPs. The authors thank Georges Bendey-Diby and Adrien Frenay for their valuable contribution to the data processing.

\section{Funding}

The BELFRAIL study [B40320084685] was supported by an unconditional grant from the Fondation Louvain. The Fondation Louvain is the support unit of the Université catholique de Louvain in charge of developing education and research projects of the university by collecting gifts from corporation, foundations and alumni. O. Dalleur was funded by the Federal Public Service Health of the Belgian government as part of a national project on implementation of clinical pharmacy in hospitals.

\section{Author details}

${ }^{1}$ Pharmacy department, Cliniques universitaires Saint-Luc, Université catholique de Louvain, Brussels, Belgium. ${ }^{2}$ Louvain Drug Research Institute (LDRI), Université catholique de Louvain, Brussels, Belgium. ${ }^{3}$ Geriatric Medicine, Cliniques universitaires Saint-Luc, Université catholique de Louvain, Brussels, Belgium. ${ }^{4}$ Ecole de Pharmacie, Université catholique de Louvain, and Centre Hospitalier Régional de Namur, Namur, Belgium. ${ }^{5}$ Institute of Health and Society Université catholique de Louvain, Brussels, Belgium. ${ }^{6}$ Department of Public Health and Primary Care, Katholieke Universiteit Leuven, Leuven, Belgium. 'Department of Family Medicine and Primary Health Care, Ghent University, Ghent, Belgium. ${ }^{8}$ Heymans Institute of Pharmacology, Ghent University, Ghent, Belgium. 'P Parmacy department, CHU Dinant-Godinne UCL Namur, Université catholique de Louvain, Yvoir, Belgium.

Received: 18 May 2015 Accepted: 16 November 2015

Published online: 02 December 2015

\section{References}

1. Hill-Taylor B, Sketris I, Hayden J, Byrne S, O'Sullivan D, Christie R. Application of the STOPP/START criteria: a systematic review of the prevalence of potentially inappropriate prescribing in older adults, and evidence of clinical, humanistic and economic impact. J Clin Pharm Ther. 2013;38(5):360-72.

2. Spinewine A, Schmader KE, Barber N, Hughes C, Lapane KL, Swine C, et al. Appropriate prescribing in elderly people: how well can it be measured and optimised? Lancet. 2007;370(9582):173-84.

3. Page 2nd RL, Ruscin JM. The risk of adverse drug events and hospital-related morbidity and mortality among older adults with potentially inappropriate medication use. Am J Geriatr Pharmacother. 2006;4(4):297-305.

4. Spinewine A, Swine C, Dhillon S, Lambert P, Nachega JB, Wilmotte L, et al. Effect of a collaborative approach on the quality of prescribing for geriatric inpatients: a randomized, controlled trial. J Am Geriatr Soc. 2007;55(5):658-65.

5. Opondo D, Eslami S, Visscher S, de Rooij SE, Verheij R, Korevaar JC, et al. Inappropriateness of medication prescriptions to elderly patients in the primary care setting: a systematic review. PLoS ONE. 2012;7(8), e43617.

6. Topinkova E, Baeyens JP, Michel JP, Lang PO. Evidence-based strategies for the optimization of pharmacotherapy in older people. Drugs Aging. 2012;29(6):477-94.

7. Beers MH, Ouslander JG, Rollingher I, Reuben DB, Brooks J, Beck JC. Explicit criteria for determining inappropriate medication use in nursing home residents. UCLA Division of Geriatric Medicine. Arch Intern Med. 1991;151(9):1825-32.

8. Fick D, Semla T, Beizer J, Brandt N, Dombrowski R, DuBeau CE, et al. American geriatrics society updated beers criteria for potentially inappropriate medication use in older adults. J Am Geriatr Soc. 2012;60(4):616-31.

9. Gallagher P, Ryan C, Byrne S, Kennedy J, O'Mahony D. STOPP (Screening Tool of Older Person's Prescriptions) and START (Screening Tool to Alert doctors to Right Treatment). Consensus validation. Int I Clin Pharmacol Ther. 2008;46(2):72-83

10. Marcum ZA, Hanlon JT. Commentary on the new American Geriatric Society Beers criteria for potentially inappropriate medication use in older adults. Am J Geriatr Pharmacother. 2012;10(2):151-9.

11. Dalleur O, Boland B, Spinewine A. 2012 updated beers criteria: greater applicability to Europe? J Am Geriatr Soc. 2012;60(11):2188-9.

12. Blanco-Reina E, Ariza-Zafra G, Ocana-Riola R, Leon-Ortiz M. 2012 American Geriatrics Society beers criteria: enhanced applicability for detecting 
potentially inappropriate medications in european older adults? a comparison with the screening tool of older Person's potentially inappropriate prescriptions. J Am Geriatr Soc. 2014;62(7):1217-23.

13. San-Jose A, Agusti A, Vidal X, Formiga F, Gomez-Hernandez M, Garcia J, et al. Inappropriate prescribing to the oldest old patients admitted to hospital: prevalence, most frequently used medicines, and associated factors. BMC Geriatr. 2015;15(1):42.

14. Dalleur O, Boland B, Losseau C, Henrard S, Wouters D, Speybroeck N, et al. Reduction of potentially inappropriate medications using the STOPP criteria in frail older inpatients: a randomised controlled study. Drugs Aging. 2014;31(4):291-8.

15. Morandi A, Vasilevskis E, Pandharipande PP, Girard TD, Solberg LM, Neal EB, et al. Inappropriate medication prescriptions in elderly adults surviving an intensive care unit hospitalization. J Am Geriatr Soc. 2013;61(7):1128-34.

16. Steinman MA, Rosenthal GE, Landefeld CS, Bertenthal D, Kaboli PJ. Agreement between drugs-to-avoid criteria and expert assessments of problematic prescribing. Arch Intern Med. 2009;169(14):1326-32.

17. Vaes B, Pasquet A, Wallemacq P, Rezzoug N, Mekouar H, Olivier PA, et al. The BELFRAIL (BFC80+) study: a population-based prospective cohort study of the very elderly in Belgium. BMC Geriatr. 2010;10:39.

18. Folstein MF, Folstein SE, McHugh PR. "Mini-mental state". A practical method for grading the cognitive state of patients for the clinician. J Psychiatr Res. 1975;12(3):189-98

19. Hudon C, Fortin M, Vanasse A. Cumulative Illness Rating Scale was a reliable and valid index in a family practice context. J Clin Epidemiol. 2005;58(6):603-8.

20. Hudon C, Fortin M, Soubhi H. Abbreviated guidelines for scoring the Cumulative IIIness Rating Scale (CIRS) in family practice. J Clin Epidemiol. 2007;60(2):212

21. Parmelee PA, Thuras PD, Katz IR, Lawton MP. Validation of the Cumulative IIIness Rating Scale in a geriatric residential population. J Am Geriatr Soc. 1995:43(2):130-7.

22. Pomeroy IM, Clark CR, Philp I. The effectiveness of very short scales for depression screening in elderly medical patients. Int I Geriatr Psychiatry. 2001;16(3):321-6

23. Tinetti ME. Performance-oriented assessment of mobility problems in elderly patients. J Am Geriatr Soc. 1986;34(2):119-26.

24. Katz S, Ford AB, Moskowitz RW, Jackson BA, Jaffe MW. Studies of illness in the aged. The index of Adl: a standardized measure of biological and psychosocial function. JAMA. 1963;185:914-9.

25. WHO. Collaborating centre for drug statistics methodology, guidelines for ATC classification and DDD assignment 2013. Oslo: WHO; 2012.

26. Guigoz Y, Vellas B, Garry PJ. Assessing the nutritional status of the elderly: The Mini Nutritional Assessment as part of the geriatric evaluation. Nutr Rev. 1996;54(1 Pt 2):S59-65.

27. Larrieu S, Peres K, Letenneur L, Berr C, Dartigues JF, Ritchie K, et al, Relationship between body mass index and different domains of disability in older persons: the 3C study. Int J Obes Relat Metab Disord. 2004;28(12):1555-60

28. Spinewine A, Dhillon S, Mallet L, Tulkens PM, Wilmotte L, Swine C. Implementation of ward-based clinical pharmacy services in Belgiumdescription of the impact on a geriatric unit. Ann Pharmacother. 2006;40(4):720-8

29. Barry PJ, Gallagher P, Ryan C, O'Mahony D. START (screening tool to alert doctors to the right treatment)-an evidence-based screening tool to detect prescribing omissions in elderly patients. Age Ageing. 2007;36(6):632-8.

30. Ryan C, O'Mahony D, Kennedy J, Weedle P, Byrne S. Potentially inappropriate prescribing in an Irish elderly population in primary care. Br J Clin Pharmacol. 2009;68(6):936-47.

31. Borges EP, Morgado M, Macedo AF. Prescribing omissions in elderly patients admitted to a stroke unit: descriptive study using START criteria. Int J Clin Pharm. 2012:34(3):481-9.

32. Vezmar Kovacevic S, Simisic M, Stojkov Rudinski S, Culafic M, Vucicevic K, Prostran $\mathrm{M}$, et al. Potentially inappropriate prescribing in older primary care patients. PLoS One. 2014;9(4), e95536.

33. Gallagher P, O'Mahony D. STOPP (Screening Tool of Older Persons' potentially inappropriate Prescriptions): application to acutely ill elderly patients and comparison with Beers' criteria. Age Ageing. 2008;37(6):673-9.

34. Cahir C, Fahey T, Teeling M, Teljeur C, Feely J, Bennett K. Potentially inappropriate prescribing and cost outcomes for older people: a national population study. Br J Clin Pharmacol. 2010;69(5):543-52.
35. Wahab M, Nyfort-Hansen K, Kowalski S. Inappropriate prescribing in hospitalised Australian elderly as determined by the STOPP criteria. Int J Clin Pharm. 2012;34(6):855-62.

36. Bradley MC, Fahey T, Cahir C, Bennett K, O'Reilly D, Parsons C, et al. Potentially inappropriate prescribing and cost outcomes for older people: a cross-sectional study using the Northern Ireland Enhanced Prescribing Database. Eur J Clin Pharmacol. 2012.

37. Onatade R, Auyeung V, Scutt G, Fernando J. Potentially inappropriate prescribing in patients on admission and discharge from an older Peoples' unit of an acute UK hospital. Drugs Aging. 2013;30(9):729-37.

38. Gallagher $\mathrm{P}, \mathrm{O}^{\prime}$ Mahony D. Inappropriate prescribing in older people. Rev Clin Gerontol. 2008;18(01):65-76.

39. Chang CB, Chan DC. Comparison of published explicit criteria for potentially inappropriate medications in older adults. Drugs Aging. 2010;27(12):947-57.

40. Lam MP, Cheung BM. The use of STOPP/START criteria as a screening tool for assessing the appropriateness of medications in the elderly population. Expert Rev Clin Pharmacol. 2012;5(2):187-97.

41. Gallagher P, Lang PO, Cherubini A, Topinkova E, Cruz-Jentoft A, Montero Errasquin $B$, et al. Prevalence of potentially inappropriate prescribing in an acutely ill population of older patients admitted to six European hospitals. Eur J Clin Pharmacol. 2011;67(11):1175-88.

42. O'Mahony D, O'Sullivan D, Byrne S, O'Connor MN, Ryan C, Gallagher P. STOPP/START criteria for potentially inappropriate prescribing in older people: version 2. Age Ageing. 2014.

43. Guaraldo L, Cano FG, Damasceno GS, Rozenfeld S. Inappropriate medication use among the elderly: a systematic review of administrative databases. BMC Geriatr. 2011;11:79.

44. Dimitrow MS, Airaksinen MS, Kivela SL, Lyles A, Leikola SN. Comparison of prescribing criteria to evaluate the appropriateness of drug treatment in individuals aged 65 and older: a systematic review. J Am Geriatr Soc 2011;59(8):1521-30.

45. Holmes HM, Min LC, Yee M, Varadhan R, Basran J, Dale W, et al. Rationalizing prescribing for older patients with multimorbidity: considering time to benefit. Drugs Aging. 2013;30(9):655-66.

46. Boyd CM, McNabney MK, Brandt N, Correa-de-Araujuo R, Daniel M Epplin J, et al. Guiding principles for the care of older adults with multimorbidity: an approach for clinicians: american geriatrics society expert panel on the care of older adults with multimorbidity. J Am Geriatr Soc. 2012:60(10):E1-E25.

\section{Submit your next manuscript to BioMed Central and we will help you at every step:}

- We accept pre-submission inquiries

- Our selector tool helps you to find the most relevant journal

- We provide round the clock customer support

- Convenient online submission

- Thorough peer review

- Inclusion in PubMed and all major indexing services

- Maximum visibility for your research

Submit your manuscript at www.biomedcentral.com/submit 